\title{
Effects of laser ablated silver nanoparticles on Lemna minor
}

\author{
Esra Üçüncü ${ }^{\mathrm{a}}$, Alper D. Özkan ${ }^{\mathrm{b}}$, Canan Kurşungöz ${ }^{\mathrm{b}}$, Zeynep E. Ülger ${ }^{\mathrm{b}}$, Tolga T. Ölmez ${ }^{\mathrm{b}}$, \\ Turgay Tekinay ${ }^{\mathrm{d}, \mathrm{e}, *}$, Bülend Ortaç ${ }^{\mathrm{b}}$, Evren Tunca ${ }^{\mathrm{b}, \mathrm{c}, \mathrm{f}, *}$ \\ ${ }^{a}$ Ankara University, Department of Biology, Faculty of Science, Ankara 06100, Turkey \\ ${ }^{\mathrm{b}}$ Bilkent University, UNAM-Institute of Materials Science and Nanotechnology, Turkey \\ c University of Muğla, Department of Geological Engineering, 48000 Kötekli, Muğla, Turkey \\ ${ }^{\mathrm{d}}$ Gazi University, Life Sciences Application and Research Center, Ankara 06830, Turkey

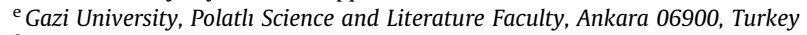 \\ ${ }^{\mathrm{f}}$ Ordu University, Faculty of Marine Sciences, 52400 Fatsa, Ordu, Turkey
}

\section{H I G H L I G H T S}

- Toxicity of laser ablated silver nanoparticles (AgNPs) on the aquatic macrophyte Lemna minor is evaluated.

- Low doses of AgNPs significantly hinder L. minor growth. Growth inhibition reaches a plateau at around $32 \mu \mathrm{g} \mathrm{L}^{-1}$.

- L. minor is a capable bioremediation agent of AgNPs, but is surpassed by unicellular organisms.

- AgNP biosorption most closely matches the Langmuir-Freundlich model; most other models are found to be unsatisfactory.

- FT-IR results suggest that carbonyl groups play a role in AgNP biosorption.

\section{A R T I C L E I N F O}

\section{Article history:}

Received 19 July 2013

Received in revised form 3 January 2014

Accepted 6 January 2014

Available online 12 February 2014

\section{Keywords:}

Nanoparticles

Silver

Toxicity

Adsorption isotherm

Growth inhibition

Lemna minor

\begin{abstract}
A B S T R A C T
The present study investigates and models the effect of laser ablated silver nanoparticles (AgNPs) on the development of the aquatic macrophyte Lemna minor. Toxic effects of five different AgNP concentrations $\left(8,16,32,96\right.$ and $\left.128 \mu \mathrm{g} \mathrm{L}^{-1}\right)$ on $L$. minor were recorded over seven days under simulated natural conditions. Biosorption of AgNPs by L. minor was modeled using four sorption isotherms, and the sorption behavior was found to agree most closely with the Langmuir-Freundlich model $\left(R^{2}=0.997\right)$. While toxic effects of AgNPs could be observed in all models and concentrations, the greatest increase in toxicity was in the $8-32 \mu \mathrm{g} \mathrm{L}^{-1}$ range. Dry weight- and frond number-based inhibition experiments suggest that growth inhibition does not necessarily scale with AgNP concentration, and that slight fluctuations in inhibition rates exist over certain concentration ranges. Very close fits $\left(R^{2}=0.999\right)$ were obtained for all removal models, suggesting that the fluctuations are not caused by experimental variation. In addition, L. minor was found to be a successful bioremediation agent for AgNPs, and displayed higher removal rates for increasing AgNP doses. FT-IR spectroscopy suggests that carbonyl groups are involved in AgNP remediation.
\end{abstract}

(ㄷ) 2014 Elsevier Ltd. All rights reserved.

\section{Introduction}

Recent developments in nanotechnology have resulted in the large-scale production of a wide array of nanoscale materials, the effects of which on the environment are still largely unknown.

\footnotetext{
* Corresponding authors. Address: Gazi University, Life Sciences Application and Research Center, Ankara 06830, Turkey. Tel.: +90 31248462 70; fax: +90 312484 6271 (T. Tekinay). Address: Ordu University, Faculty of Marine Sciences, Department of Marine Sciences and Technology, 52400 Fatsa, Ordu, Turkey. Tel.: +90 452 42350 53/4707; fax: +90 3122232395 (E. Tunca).

E-mail addresses: ttekinay@gmail.com (T. Tekinay), evren_tunca@yahoo.com (E. Tunca).
}

Nanoparticles may demonstrate vastly different properties compared to their bulk equivalents, and their small $(1-100 \mathrm{~nm})$ sizes, corresponding to high specific surface areas and mobilities, are thought to render them potentially hazardous to human and environmental health (Wiesner et al., 2006). Extensive production and use of nanoparticles may result in their accidental release in aquatic ecosystems, where they may have detrimental effects on a wide spectrum of organisms (Navarro et al., 2008). However, the determination of nanoparticle toxicities has received little attention until recent times, and thorough ecological and toxicological evaluations are necessary to fully understand the potential impact that nanoscale contaminants may have on the environment. 
Due to their wide-spectrum antibiotic activity, Ag nanoparticles (AgNPs) have been commonly incorporated into textiles, cosmetics, paints and food additives (He et al., 2012). AgNPs are conventionally synthesized by the treatment of an $\mathrm{Ag}$ salt with a reducing agent, but can also be produced by a diverse array of alternative synthesis methods, including electrolysis, photoreduction, pyrolysis, sol-gel methods and biological material-mediated reduction (Evanoff and Chumanov, 2005; Pingali et al., 2005; Reisfeld et al., 2008). Laser ablation in particular has drawn considerable attention as a potent method for the generation of nanoparticles from bulk silver or other metals, as this technique does not require the long reaction times, high temperatures, purity-compromising reduction agents or other toxic materials associated with competing synthesis methods (Semaltianos, 2010).

No matter their source of origin, the high mobility of AgNPs allows a portion of these nanoparticles to accumulate in aquatic environments (Reidy et al., 2013). However, while it is known that Ag cations are toxic to a number of organisms (Wood et al., 1996; Ratte, 1999; Prasad et al., 2001), research performed on the effects of $\mathrm{Ag}$ nanoparticles on aquatic life have been limited (Turner et al., 2012). The characterization of $\mathrm{Ag}$ nanoparticle fates in aquatic environments is therefore crucial.

Aquatic plants are the most prominent primary producers in freshwater ecosystems, forming the base of aquatic food chains and balancing the ecosystem by limiting or encouraging the spread and proliferation of animal populations (Jiang et al., 2012). As such, the aquatic macrophyte Lemna minor was chosen as the model organism in this study. Due to its high reproductive rate, small size and ease of cultivation and harvest, $L$. minor is an ideal model for toxicology research and has been used extensively for the determination of heavy metal and nanoparticle toxicities (Rakhshaee et al., 2009; Li et al., 2013; Üçüncü et al., 2013).

The present study aims to understand the effects of Ag nanoparticle toxicity on the environment by modeling the effects of AgNPs on L. minor growth and development. Toxicities of five different AgNP concentrations on $L$. minor were modeled separately in a dose- and time-dependent manner, FT-IR spectroscopy was employed to identify the biochemical changes caused by interaction with AgNPs, and nanoparticle biosorption rates were determined by kinetic modeling and sorption isotherms to evaluate the extent of AgNP remediation from aquatic ecosystems by L. minor.

\section{Materials and methods}

\subsection{Production and characterization of AgNPs}

A 0.25 -inch cylindrical silver pellet (99.99\% purity; Kurt J. Lesker Company) in deionized water was used to produce AgNPs (Deniz et al., 2011; Alkis et al., 2012a, b). Laser ablation was performed using a commercial nanosecond pulsed ND:YLF laser (Empower Q-Switched Laser, Spectra Physics) operating at $527 \mathrm{~nm}$, with a pulse duration of $100 \mathrm{~ns}$, average output power of $16 \mathrm{~W}$ and pulse repetition rate of $1 \mathrm{kHz}$ (corresponding to a pulse energy of $16 \mathrm{~mJ}$ ). The silver block was placed in a glass vessel containing $20 \mathrm{~mL}$ deionized water; the height of the water layer over the target was approximately $5 \mathrm{~mm}$. The laser beam was focused on the target using a plano-convex lens with a focal length of $50 \mathrm{~mm}$. Laser ablation was performed for 5 min by scanning the laser beam over the target surface, nanoparticle formation was confirmed visually by the change of the medium color from colorless to yellow.

The silver block was weighed before and after the ablation process; the weight difference was used to calculate a final nanoparticle concentration of $3.3 \mathrm{mg} \mathrm{AgNP} / 25 \mathrm{~mL}$ deionized water. The accuracy of this calculation, as well as the purity of the AgNP sample, was evaluated by the inductively coupled plasma mass spectrometry (ICP-MS) analysis of a $40 \mu \mathrm{g} \mathrm{L}{ }^{-1}$ AgNP suspension (see Section 2.3.1 for ICP-MS analysis conditions). The Ag concentration in the sample was measured to be $37.570 \pm 1.831 \mu \mathrm{g} \mathrm{L}^{-1}$, confirming the reliability of the weight difference analysis. The stability of the AgNP suspension was determined by the ICP-MS analysis of the same $40 \mu \mathrm{g} \mathrm{L}^{-1}$ sample after $19 \mathrm{~d}$.

The morphology of AgNPs was determined by the use of a transmission electron microscope (TEM) (FEI-Tecnai G2F30) alongside Energy Dispersive X-ray (EDX) analysis. TEM samples were prepared by dropcasting the AgNP solution onto a carbon-coated TEM grid. UV-Vis-NIR spectrophotometer (Varian Cary 5000) analysis was performed to determine the absorbance spectrum of AgNPs. In addition, the sizes and surface charges of the AgNPs were measured using a dynamic light scattering (DLS) device (Malvern Zetasizer Nano ZS).

\subsection{Cultivation of L. minor}

Specimens of L. minor were procured from Ankara University, Faculty of Science greenhouse cultures and acclimated to laboratory conditions for 4 weeks. Cultures were grown in water native to the greenhouse, and were not externally supplied with water throughout the experimental period. Water aliquots taken from culture samples were filtrated with a $0.22 \mu \mathrm{m}$ filtration unit (Nalgene filter unit, Fisher Scientific, USA) prior to testing. All experiments were carried out in alkaline conditions, initial $\mathrm{pH}$ values were found to be in the 8.80-9.20 range. Other parameters of test groups are listed as follows: Temperature: $23.8-24.2{ }^{\circ} \mathrm{C}$, TDS ( $\left.\mathrm{mg} \mathrm{L}^{-1}\right): 254-291, \mathrm{EC}(\mathrm{SPC})\left(\mu \mathrm{S} \mathrm{cm}^{-1}\right): 392-448, \mathrm{EC}(\mathrm{C})\left(\mu \mathrm{S} \mathrm{cm}^{-1}\right)$ : 386-446, Salinity (ppt): $0.16-0.22, \mathrm{DO}_{2}\left(\mathrm{mg} \mathrm{L}^{-1}\right): 4.80-5.08$ and $\mathrm{NO}_{3}\left(\mathrm{~N}^{\mathrm{mg} \mathrm{L}}{ }^{-1}\right): 1.15-2.50$. Initial metal concentrations of samples were measured by ICP-MS (see Section 2.3.1 for analysis details) and are as follows: $\mathrm{Cr}$ : 1.84-4.37, Mn: 0.09-0.56, Fe: 350-631, Co: 0.23-0.33, Ni: 4.19-5.92, Cu: 2.78-7.17, As: 3.3-4.38, Ag: ND-0.1, Cd: 0.01-0.05, Pb: 0.04-0.6 (all values $\mu \mathrm{g} \mathrm{L}^{-1}$ ). The detection limit for $\mathrm{Ag}$ was found to be $0.02 \mu \mathrm{g} \mathrm{L}^{-1}$. Samples were constantly exposed to fluorescent lamps ( $24 \mathrm{~h}$ light $/ 0 \mathrm{~h}$ dark cycles) (Sekomo et al., 2012)

\subsection{Silver exposure and removal studies}

All experiments were conducted using $100 \mathrm{~mL}$ filtered greenhouse water in $200 \mathrm{~mL}$ plastic containers. Containers were cleaned by $10 \% \mathrm{HNO}_{3}$ and washed thrice with $\mathrm{ddH}_{2} \mathrm{O}$ prior to use. Tops of the test containers were covered in order to prevent evaporation and accidental contamination.

A $3.3 \mathrm{mg} / 25 \mathrm{~mL}$ (132 $\left.\mathrm{mg} \mathrm{L}^{-1}\right)$ silver nanoparticle stock solution was utilized for all experiments. L. minor samples were exposed to five different nanoparticle concentrations (8, 16, 32, 96 and $\left.128 \mu \mathrm{g} \mathrm{L}^{-1}\right)$ and controls lacking nanoparticle spiking $\left(0 \mu \mathrm{g} \mathrm{L}^{-1}\right)$. Nanoparticle removal and toxicity tests were run for seven days and conducted in triplicate. $L$. minor specimens with two to three fronds per specimen were utilized for all tests; each sample group consisted of 21 fronds in total. Starting from the 24th hour, the physical condition of $L$. minor fronds were observed and photographed throughout the test.

For AgNP uptake studies, $10 \mathrm{~mL}$ aliquots were taken from each container at the end of the seven-day experimental period, filtered, and analyzed in a $2 \%$ nitric acid matrix using an X-Series II ICP-MS (Thermo Fisher Scientific Advanced Mass Spectrometry, Bremen, Germany).

Frond numbers were counted every 24 h to determine plant growth. The average specific growth rate of $L$. minor was calculated using the following formula (OECD, 2002): 
$\mu_{i-j}=\frac{\ln \left(N_{j}\right)-\ln \left(N_{i}\right)}{t_{j}-t_{i}}$

$\mu_{i-j}$ is the average specific growth rate between times $i$ and $j ; N_{j}$ the number of fronds observed in the test or control vessel at time $j ; N_{i}$ the number of fronds observed in the test or control vessel at time $i$; $t_{i}$ the time of experiment initiation; $t_{j}$ is the time of experiment closure.
To eliminate potential issues with unequal frond sizes, developing fronds were given coefficient values of $0.25,0.50$ or 0.75 , depending on their surface areas. Mature fronds were given area coefficients of 1.0. Growth rates were determined by frond numbers and dry weights at the end of the experiment period. Frond dry weights were also utilized to calculate biomass inhibition percentages, and were measured after washing day 7 samples
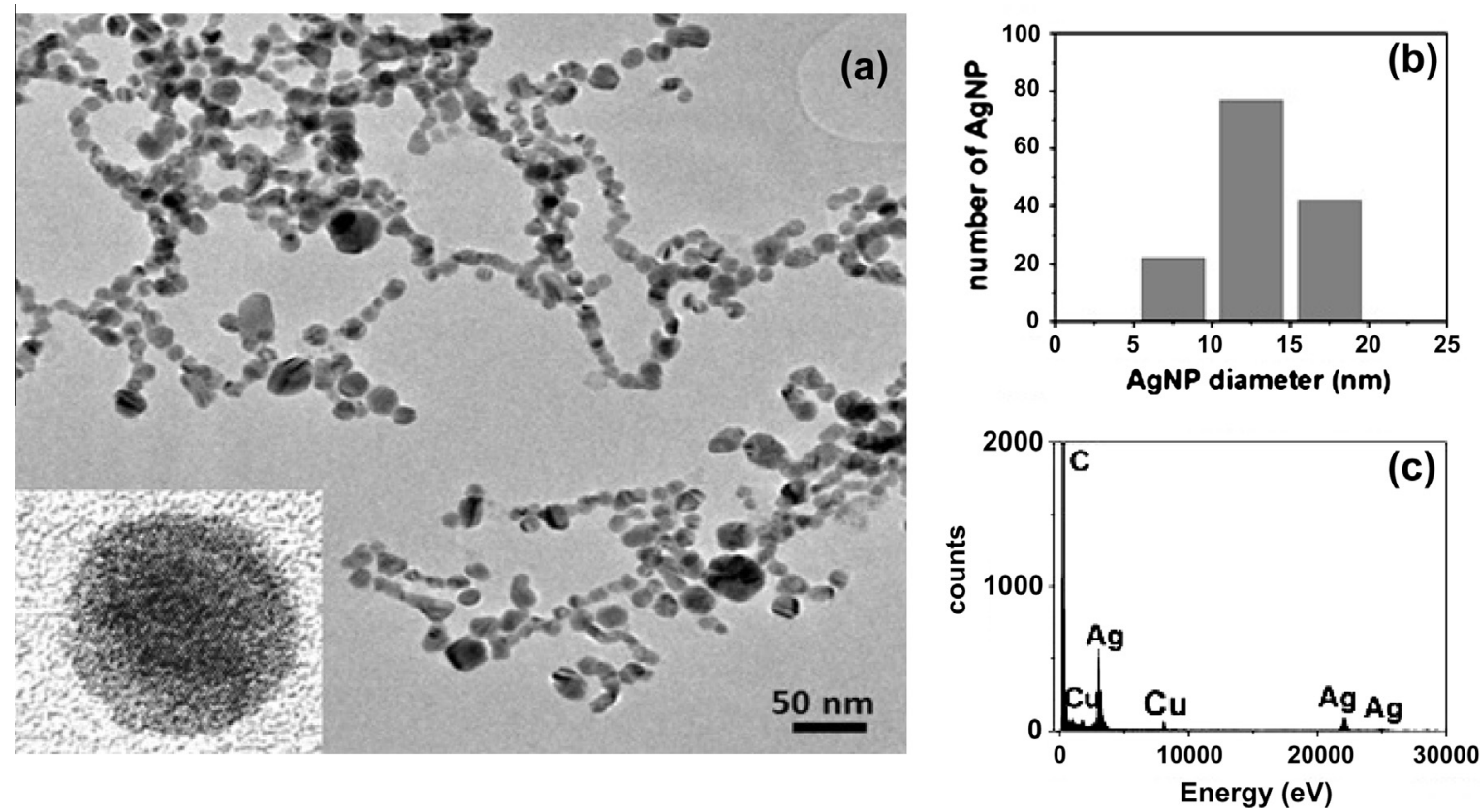

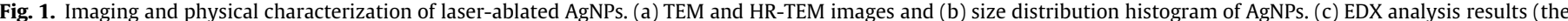
grid utilized for TEM imaging is responsible for the $\mathrm{C}$ - and $\mathrm{Cu}$-associated peaks).

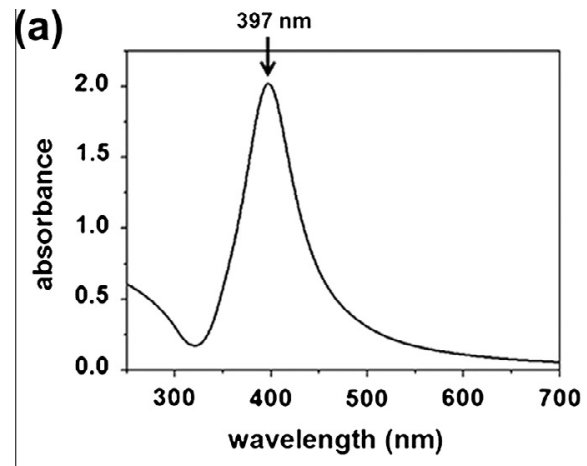

(b)

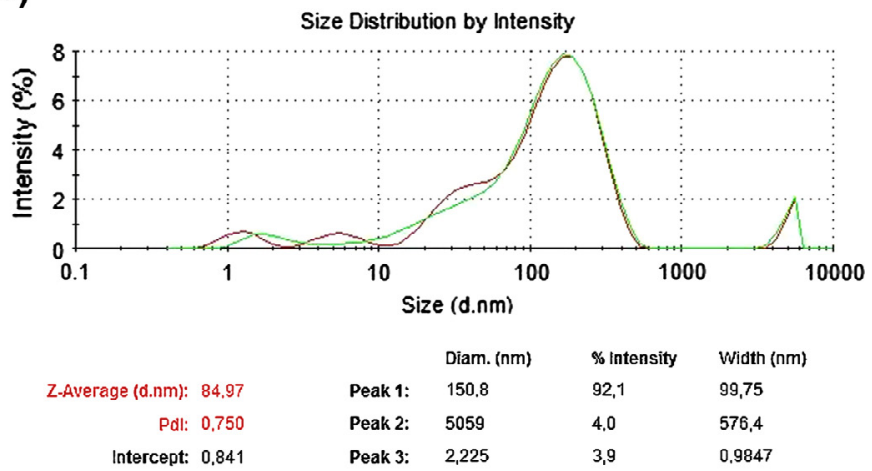

(c)

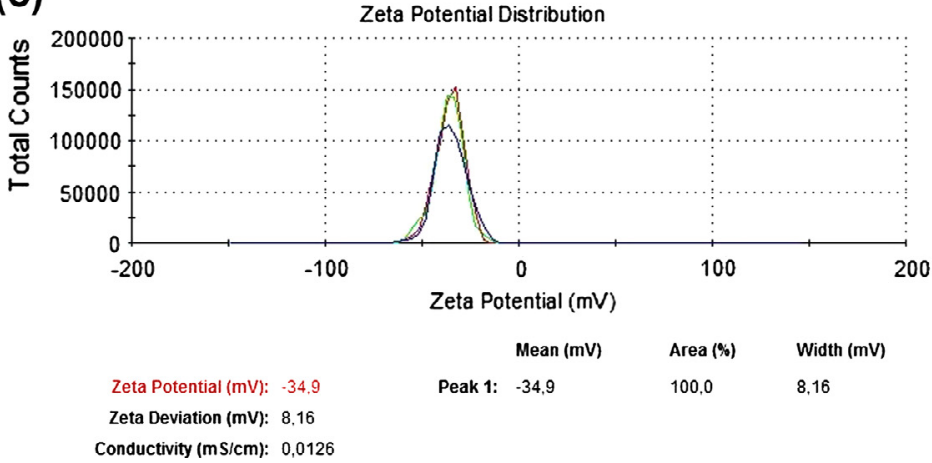

Fig. 2. Spectrometric characterization of laser-ablated AgNPs. (a) UV-Vis absorption spectrum of AgNPs. (b) Size distribution and (c) Zeta potential of AgNPs. 
with distilled water and oven-drying overnight at $105^{\circ} \mathrm{C}$. Growth inhibition rates were calculated using the following formula (OECD, 2002):

$\% I_{b}=\frac{\left(b_{c}-b_{T}\right)}{b_{c}} \times 100$

$\% I_{b}$ is the percent inhibition in average specific growth rate; $b_{c}$ the mean value of $\mathrm{m}$ in control; $b_{T}$ is the mean value of $\mathrm{m}$ in treatment group.
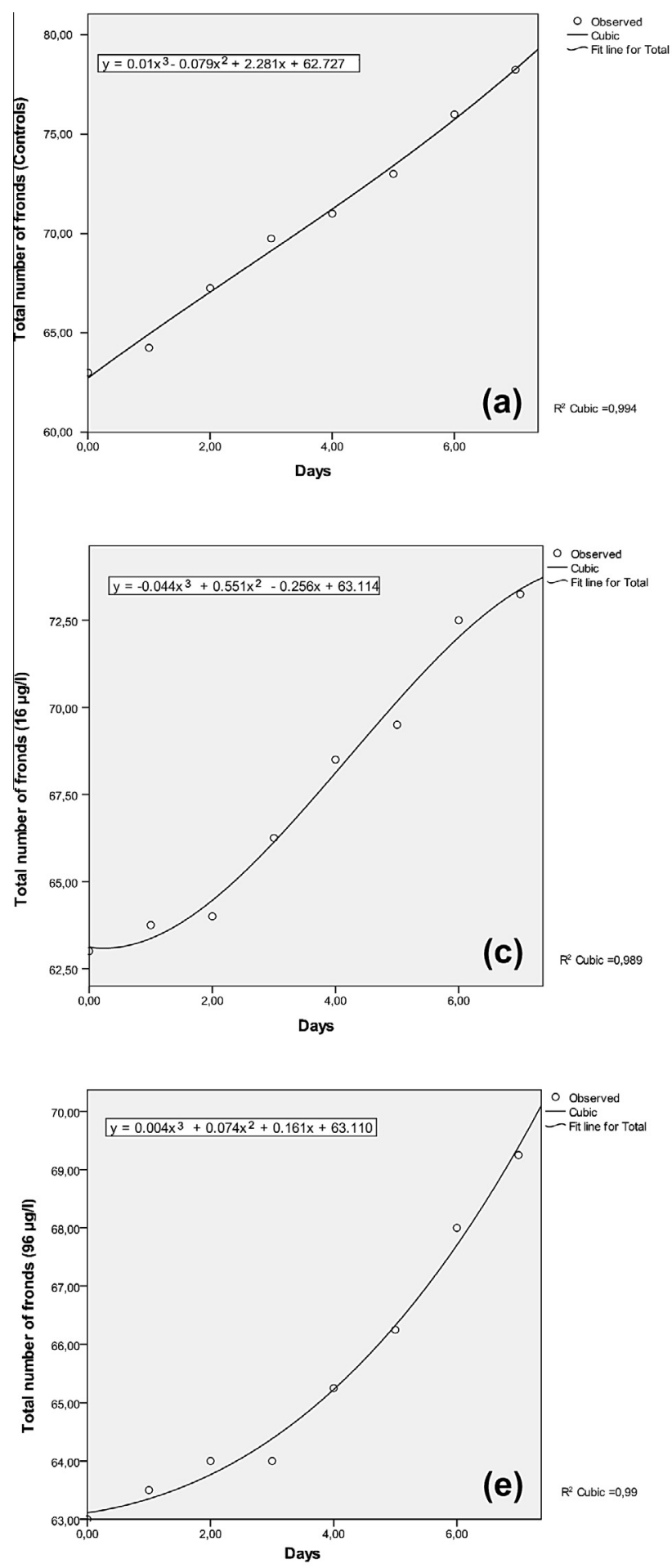

Regression analysis was performed for all models using SPSS 17 (IBM, Portsmouth, UK). In addition, the AgNP removal data was fit to four sorption isotherm models (Freundlich, Langmuir, Langmuir-Freundlich and Toth) using the isotherm fitting tool IsoFit (Matott and Rabideau, 2008).

\subsubsection{ICP-MS analysis}

An X-Series II ICP-MS (Thermo Fisher Scientific Advanced Mass Spectrometry, Bremen, Germany), equipped with a Cetac Asx-260 autosampler accessory, was utilized for ICP-MS measurements.
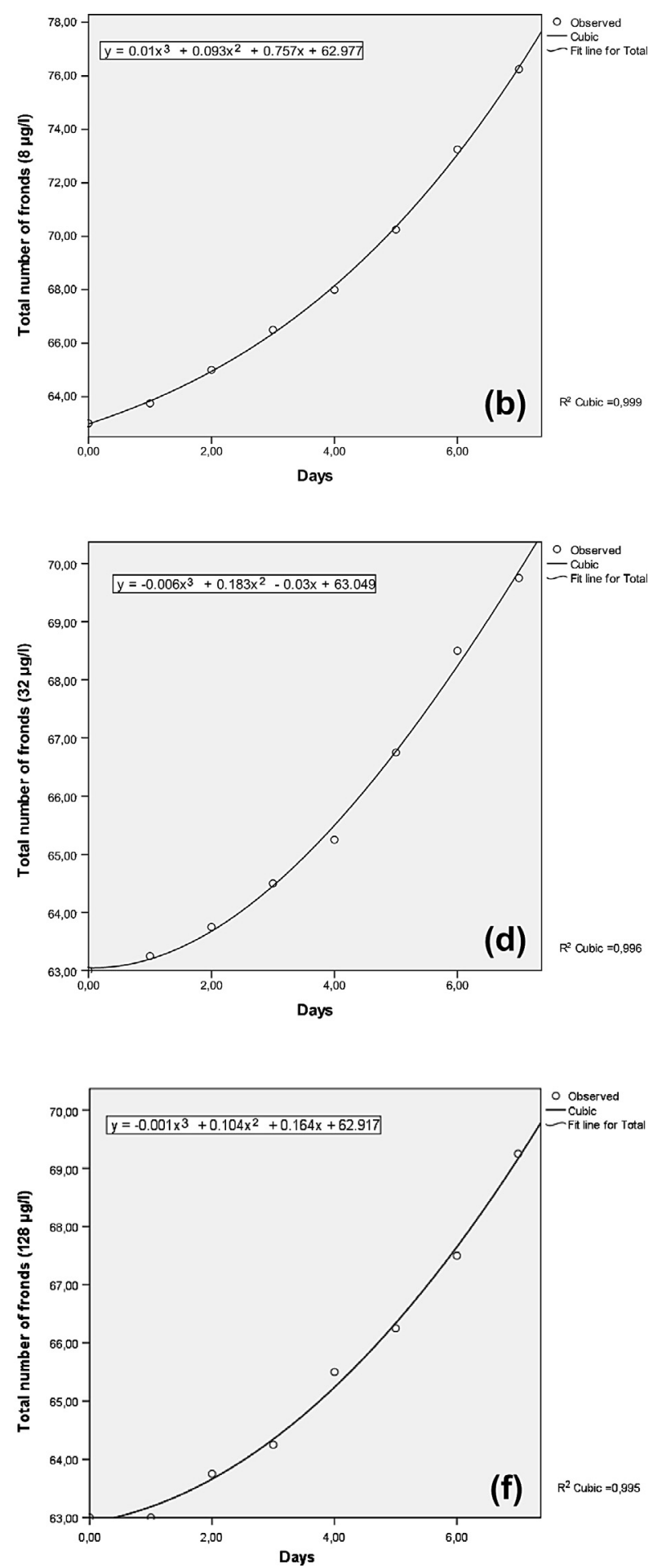

Fig. 3. Frond development rate models for (a) control $\left(0 \mu \mathrm{g} \mathrm{L}^{-1}\right)$ and (b) 8, (c) 16 , (d) 32 , (e) 96 and (f) $128 \mu \mathrm{g} \mathrm{L}^{-1}$ samples. 
All standard curves were prepared using the QCS-27 series of elements (High Purity Standards, South Carolina, USA). Expected metal concentration ranges in each test group were taken into account in the construction of standard curves, and a correlation coefficient over 0.990 was obtained for each curve. Bismuth was utilized as an internal standard. Three runs were conducted for each sample; sampling and washing times were $60 \mathrm{~s}$ each.

\subsubsection{FT-IR spectroscopy}

FT-IR spectra were recorded over the wavenumber range 4000$400 \mathrm{~cm}^{-1}$ using a VERTEX 70 FT-IR spectrometer (Bruker, Massachusetts, USA). Two frond samples from each group were frozen in liquid nitrogen, homogenized by crushing, mixed with $100 \mathrm{mg}$ $\mathrm{KBr}$ and pressed prior to measurement. Spectra were baselined prior to analysis.

\section{Results and discussion}

\subsection{Nanoparticle characterization}

A representative TEM image of AgNPs is presented in Fig. 1a. AgNPs were observed to be spherical in shape and bore a uniform dispersion pattern without significant aggregations. The TEM image also suggests that the AgNPs are crystalline, which can be deduced from the lattice fringes of the HR-TEM image of a single isolated $13 \mathrm{~nm} \mathrm{AgNP}$ (Fig. 1a, inset). Sizes of 150 particles were recorded to evaluate the uniformity of size distribution in laser ablated AgNPs, the greatest number of particles were found to be in the size range of 5-20 nm (Fig. 1b). While AgNPs with diameter sizes of $20-50 \mathrm{~nm}$ were present in the solution, those particles had abundances lower than $10 \%$ and were not included in the histogram. Barring carbon and copper signatures from TEM grids, EDX analysis exclusively displayed peaks corresponding to silver (Fig. 1c), suggesting that a pure AgNP solution was produced by the nanosecond laser ablation method.

UV-Vis absorption spectroscopy was performed for the further investigate the physical characteristics of AgNPs. The nanoparticles displayed an absorption peak at $397 \mathrm{~nm}$ (Fig. 2a), which agrees with previous reports on the UV-Vis spectra of laser-ablated AgNPs (Akman et al., 2011). Contrary to TEM imaging, DLS measurements indicate that the mean nanoparticle size is closer to $84.97 \mathrm{~nm}$ (Fig. 2b), suggesting that larger nanoparticles dominate in total mass despite their relative scarcity in number. The nanoparticles were found to display a zeta potential of $-34.9 \mathrm{mV}$ (Fig. 2c), which is sufficiently high to prevent aggregations over the time periods required by the AgNP removal tests. The stability of the AgNP suspension was further confirmed by the ICP-MS analysis of a $40 \mu \mathrm{g} \mathrm{L}^{-1}$ sample after $19 \mathrm{~d}$; the sample retained an AgNP concentration of $39.690 \pm 1.205 \mu \mathrm{g} \mathrm{L}^{-1}$ following this time period. The concentrations of ${ }^{27} \mathrm{Al},{ }^{47} \mathrm{Ti},{ }^{52} \mathrm{Cr},{ }^{55} \mathrm{Mn},{ }^{57} \mathrm{Fe},{ }^{59} \mathrm{Co},{ }^{60} \mathrm{Ni},{ }^{65} \mathrm{Cu},{ }^{66} \mathrm{Zn}$, ${ }^{75} \mathrm{As},{ }^{95} \mathrm{Mo},{ }^{111} \mathrm{Cd}$ and ${ }^{208} \mathrm{~Pb}$ in a $40 \mu \mathrm{g} \mathrm{L}{ }^{-1}$ suspension of AgNPs were found to be $1.17 \pm 0.002,0.214 \pm 0.030,0.023 \pm 0.004$, $0.013 \pm 0.003, \quad 1.719 \pm 0.325, \quad 0.027 \pm 0.047, \quad 0.021 \pm 0.001$, $0.031 \pm 0.002, \quad 24.680 \pm 0.396, \quad 0.085 \pm 0.008, \quad 0.011 \pm 0.001$, $0.002 \pm 0.002$ and $0.028 \pm 0.001 \mu \mathrm{g} \mathrm{L}^{-1}$, respectively.

\subsection{Effect of AgNPs on L. minor}

L. minor frond growth models are provided for all samples in Fig. 3a-f. Daily frond growths appear to be logarithmic for all AgNP concentrations. However, control samples display a linear-like growth, and linear regression modeling yields a $R^{2}$ value of 0.993 for this group. This result is roughly equal to the $R^{2}$ value of 0.994 given by the cubic equation. The logarithmic growth observed in AgNP-exposed L. minor fronds, in contrast to the linear growth of control samples, can be explained by the decrease of
AgNP toxicity experienced over time. Higher AgNP concentrations at experimental initiation may have led to a sharp decrease in growth rate, which would later be alleviated either by remediation of AgNPs by L. minor or the activation of stress tolerance mechanisms in the plant. Consequently, frond growth is expected to be slowed until such compensatory mechanisms can be activated, which is supported by our observations. Removal of AgNPs has been confirmed by the determination of $\mathrm{Ag}$ in water samples at experiment initiation and closure. Increasing concentrations were found to correlate with increasing AgNP removal, a result supported with very high confidence $\left(R^{2}=0.999\right)$ by our models (Fig. 4). This trend is expected to continue until a certain concentration, beyond which a decrease and eventual stop of AgNP removal may occur due to the plants expiring too rapidly for efficient removal to occur. Further research is needed to determine the point at which AgNP removal is unfeasible.

Removal of AgNPs from the surrounding medium was modeled using four isotherm models (Freundlich, Langmuir, Langmuir-Freundlich and Toth) to evaluate the efficiency of $L$. minor as a potential remediation agent of AgNPs. Sorption models generally assume that the total number of sorption sites remains constant over the tested concentration range. This assumption may not hold for growing Lemna fronds, since the plant may respond to higher doses of AgNPs by activating compensatory mechanisms (e.g. stress response genes). As such, predictive successes of the isotherms in question were relatively low $\left(R^{2}<0.8\right.$ for most models). However, the Langmuir-Freundlich model proved highly capable of predicting removal values $\left(R^{2}=0.997\right)$ and yielded a maximum AgNP removal $\left(Q_{\max }\right)$ value of $18.73 \mathrm{mg}$ AgNP per gram Lemna tissue (other values associated with this isotherm are $K_{a}=0.0346$ and $1 / n=1.98$, where $K_{a}$ is an empirical constant and $1 / n$ is the Langmuir-Freundlich isotherm exponent). This value is lower than those previously reported for silver nanoparticle removal by

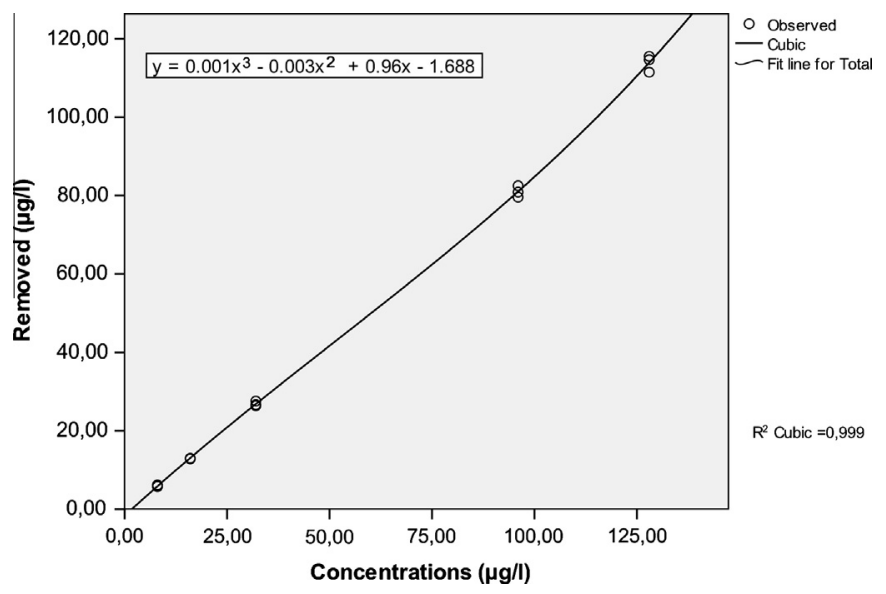

Fig. 4. Dose-dependent model of AgNP removal at day 7.

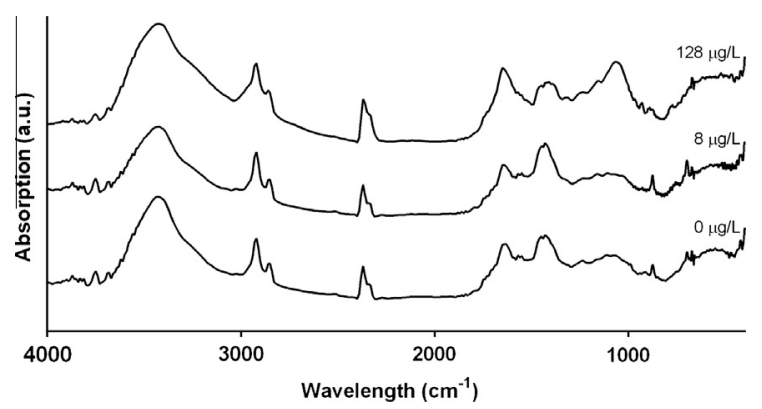

Fig. 5. FT-IR spectra of control $\left(0 \mu \mathrm{g} \mathrm{L}^{-1}\right), 8$ and $128 \mu \mathrm{g} \mathrm{L^{-1 }}$ samples at day 7 in the $4000-400 \mathrm{~cm}^{-1}$ region. 
bacteria (e.g. $43.27 \mathrm{mg} \mathrm{g}^{-1}$ for Corynebacterium glutamicum active biomass under the Langmuir model), likely because $L$. minor is multicellular and therefore presents fewer sorption sites per unit mass compared to single-celled organisms (Sneha et al., 2010).

FT-IR spectra of control $\left(0 \mu \mathrm{g} \mathrm{L}^{-1}\right), 8 \mu \mathrm{g} \mathrm{L} \mathrm{L}^{-1}$ and $128 \mu \mathrm{g} \mathrm{L}^{-1}$ fronds are provided in Fig. 5. Spectra of control and $8 \mu \mathrm{g} \mathrm{L}^{-1}$ samples were largely similar to each other, while the $128 \mu \mathrm{g} \mathrm{L}^{-1}$ sample displayed considerable differences. A significant intensity increase in the $1040-1080 \mathrm{~cm}^{-1}$ region was noted in the latter sample, corresponding to a carbonyl peak and suggesting that carbonyl groups may be involved in AgNP remediation. Likewise, the amide I peak at $1650 \mathrm{~cm}^{-1}$ (which corresponds to protein carbonyl groups) broadens in the $128 \mu \mathrm{g} \mathrm{L}^{-1}$ sample, supporting the idea that carbonyl groups may facilitate AgNP removal. Carbonyl and ionized carboxyl groups have previously been implicated in silver adsorption, and L. minor specimens may be altering their metabolic contents in order to better reduce or sequester AgNPs (Pethkar et al., 2001; Zhang et al., 2005). We note that the changes in question may in part be caused by differences in Lemna tissue masses in the samples, since frond numbers were used as basis in place of total mass. However, above-mentioned differences remain when the carbonyl peaks at $1075 \mathrm{~cm}^{-1}$ is normalized using other peaks (e.g. the broad hydroxyl peak around $3450 \mathrm{~cm}^{-1}$ or the $\mathrm{C}-\mathrm{H}$ stretching peak at $2920 \mathrm{~cm}^{-1}$ ) as reference (Villaescusa et al., 2004).

Growth rates were generally observed to decrease with increasing silver concentrations (Fig. 6a), and our results suggest that
AgNP concentrations as low as $8 \mu \mathrm{g} \mathrm{L}^{-1}$ can have a toxic effect on Lemna growth. This toxicity is observed as a pronounced repression of growth in our frond number-based models. The effect of silver nanoparticles on Lemna growth becomes more prominent as nanoparticle concentration increases. Similar results have been obtained in a prior study investigating the toxicity of AgNPs on $L$. minor under acidic conditions $(\mathrm{pH}=5.5 \pm 1.4)$, where lowest growth rates were observed under the highest concentration $\left(128 \mu \mathrm{g} \mathrm{L}^{-1}\right)$. Studies on other nanoparticles have yielded similar results, e.g. Al nanoparticles were found to decrease frond numbers with increasing concentrations over a $10-1000 \mathrm{mg} \mathrm{L}^{-1}$ range (Juhel et al., 2011). While prior research on $\mathrm{TiO}_{2}$ reports an increase in L. minor growth at low concentrations $\left(<200 \mathrm{mg} \mathrm{L}^{-1}\right)$, higher concentrations still result in growth inhibition (Song et al., 2012).

Despite the general increase in growth repression with increasing AgNP concentrations, it is notable that the decrease in frond growth between $8 \mu \mathrm{g} \mathrm{L}^{-1}$ and $32 \mu \mathrm{g} \mathrm{L}^{-1}$ samples is greater than the decrease between $32 \mu \mathrm{g} \mathrm{L}^{-1}$ and $128 \mu \mathrm{g} \mathrm{L}^{-1}$ samples, suggesting that the greatest impact is made over a lower concentration range. No significant change in growth repression was observed between $96 \mu \mathrm{g} \mathrm{L}^{-1}$ and $128 \mu \mathrm{g} \mathrm{L}^{-1}$ samples, which represent the highest concentrations tested. However, our models suggest that pronounced decreases in growth rates will continue to occur at concentrations higher than $128 \mu \mathrm{g} \mathrm{L}^{-1}$.

Dry weight and frond number results appear not to correlate directly with concentration increases, and slight fluctuations in
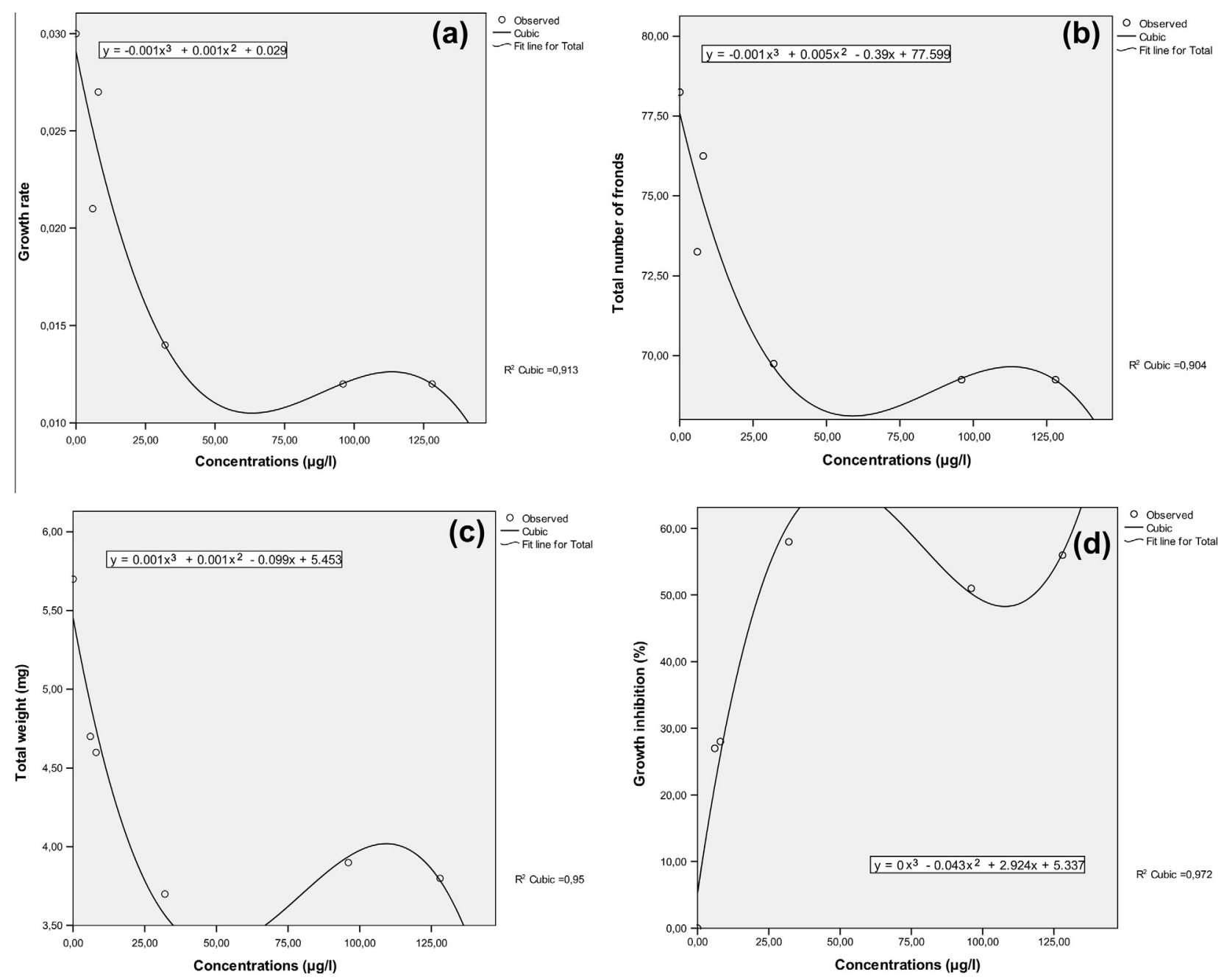

Fig. 6. Dose-dependent models of (a) growth rate, (b) frond numbers (c) frond weights, and (d) growth inhibition at day 7. 
toxicity-concentration interactions are observed at certain concentrations (Fig. 6b and c). In a prior study by Gubbins et al., different sizes of Ag nanoparticles were found to alter dry weight and frond numbers in different manners (Gubbins et al., 2011). The present study, however, does not distinguish between nanoparticle sizes.

Biomass inhibition models of all test groups are presented in Fig. 6d. Our results suggest that the greatest inhibition rate occurs at $32 \mu \mathrm{g} \mathrm{L}^{-1}$ (58\%). A similar result was also observed by Gubbins et al., who recorded a $100 \%$ inhibition rate at $40 \mu \mathrm{g} \mathrm{L}^{-1}$ for Ag cations.

Overall, our results demonstrate that AgNPs can inhibit L. minor growth even at the lowest doses tested. Nanoparticle toxicity increases with higher concentrations, albeit with a slight decrease at the $75-110 \mu \mathrm{g} \mathrm{L}^{-1}$ range for all models. Certain dose ranges are known to be associated with fluctuations in toxicity for a number of toxic materials (Juhel et al., 2011; Manzo et al., 2013; Oukarroum et al., 2013). We propose that this change is due to potential defensive measures by the plant and not the result of an experimental artifact, as the aforementioned fluctuation in the $75^{-1} 10 \mu \mathrm{g} \mathrm{L}^{-1}$ range was consistently observed in total frond number, frond weight, growth and biomass inhibition analyses.

\section{Conclusion}

While AgNPs are known to be environmental hazards, the precise extent of their toxic effects has seldom been demonstrated. In this study, we evaluate the toxic effects of AgNPs on the environment by using the aquatic macrophyte $L$. minor. Dose- and timedependent toxicity models suggest that AgNP toxicity on L. minor increases rapidly over low concentration ranges $\left(8-32 \mu \mathrm{g} \mathrm{L}^{-1}\right)$, while concentration-dependent toxicity increases are much less pronounced (and subject to more significant fluctuations) at higher concentrations. In lower concentration ranges, slight increases in AgNP concentrations correspond to dramatic increases in toxicity, which may be ecologically significant as accidental introduction of low amounts of AgNPs on freshwater environments may be greatly detrimental to the ecosystem in general and aquatic macroflora in particular. In addition, $L$. minor was found to be capable of AgNP removal at a maximum capacity of $18.73 \mathrm{mg} \mathrm{AgNP/g} \mathrm{Lemna}$ dry biomass, suggesting that the plant may be utilized for the bioremediation of silver nanoparticles.

\section{References}

Akman, E., Oztoprak, B.G., Gunes, M., Kacar, E., Demir, A., 2011. Effect of femtosecond Ti:Sapphire laser wavelengths on plasmonic behaviour and size evolution of silver nanoparticles. Photonic Nanostruct. 9, 276-286.

Alkis, S., Okyay, A.K., Ortac, B., 2012a. Post-treatment of silicon nanocrystals produced by ultra-short pulsed laser ablation in liquid: toward blue luminescent nanocrystal generation. J. Phys. Chem. C 116, 3432-3436.

Alkis, S., Oztas, T., Aygun, L.E., Bozkurt, F., Okyay, A.K., Ortac, B., 2012b. Thin film $\mathrm{MoS}_{2}$ nanocrystal based ultraviolet photodetector. Opt. Express 20, 21815 21820.

Deniz, A.E., Vural, H.A., Ortac, B., Uyar, T., 2011. Gold nanoparticle/polymer nanofibrous composites by laser ablation and electrospinning. Mater. Lett. 65, 2941-2943.

Evanoff Jr., D.D., Chumanov, G., 2005. Synthesis and optical properties of silver nanoparticles and arrays. ChemPhysChem 6, 1221-1231.

Gubbins, E.J., Batty, L.C., Lead, J.R., 2011. Phytotoxicity of silver nanoparticles to Lemna minor L. Environ. Pollut. 159, 1551-1559.
He, D., Dorantes-Aranda, J.J., Waite, T.D., 2012. Silver nanoparticle-algae interactions: oxidative dissolution, reactive oxygen species generation and synergistic toxic effects. Environ. Sci. Technol. 46, 8731-8738.

Jiang, H.S., Li, M., Chang, F.Y., Li, W., Yin, L.Y., 2012. Physiological analysis of silver nanoparticles and AgNO3 toxicity to Spirodela polyrhiza. Environ. Toxicol. Chem. SETAC 31, 1880-1886.

Juhel, G., Batisse, E., Hugues, Q., Daly, D., van Pelt, F.N., O’Halloran, J., Jansen, M.A., 2011. Alumina nanoparticles enhance growth of Lemna minor. Aquat. Toxicol. 105, 328-336.

Li, L., Sillanpaa, M., Tuominen, M., Lounatmaa, K., Schultz, E., 2013. Behavior of titanium dioxide nanoparticles in Lemna minor growth test conditions. Ecotoxicol. Environ. Saf. 88, 89-94.

Manzo, S., Miglietta, M.L., Rametta, G., Buono, S., Di Francia, G., 2013. Toxic effects of ZnO nanoparticles towards marine algae Dunaliella tertiolecta. Sci. Total Environ. 445, 371-376.

Matott, L.S., Rabideau, A.J., 2008. ISOFIT - a program for fitting sorption isotherms to experimental data. Environ. Modell. Softw. 23, 670-676.

Navarro, E., Piccapietra, F., Wagner, B., Marconi, F., Kaegi, R., Odzak, N., Sigg, L., Behra, R., 2008. Toxicity of silver nanoparticles to Chlamydomonas reinhardtii. Environ. Sci. Technol. 42, 8959-8964.

OECD, 2002. Guidelines for the testing of chemicals. Lemna sp. Growth inhibition test. Draft guideline OECD, 221.

Oukarroum, A., Barhoumi, L., Pirastru, L., Dewez, D., 2013. Silver nanoparticle toxicity effect on growth and cellular viability of the aquatic plant Lemna gibba. Environ. Toxicol. Chem. 32, 902-907.

Pethkar, A.V., Kulkarni, S.K., Paknikar, K.M., 2001. Comparative studies on metal biosorption by two strains of Cladosporium cladosporioides. Bioresour. Technol. $80,211-215$.

Pingali, K.C., Rockstraw, D.A., Deng, S.G., 2005. Silver nanoparticles from ultrasonic spray pyrolysis of aqueous silver nitrate. Aerosol Sci. Technol. 39, 1010-1014.

Prasad, M.N.V., Malec, P., Waloszek, A., Bojko, M., Strzalka, K., 2001. Physiological responses of Lemna trisulca L. (duckweed) to cadmium and copper bioaccumulation. Plant Sci. 161, 881-889.

Rakhshaee, R., Giahi, M., Pourahmad, A., 2009. Studying effect of cell wall's carboxyl-carboxylate ratio change of Lemna minor to remove heavy metals from aqueous solution. J. Hazard. Mater. 163, 165-173.

Ratte, H.T., 1999. Bioaccumulation and toxicity of silver compounds: a review. Environ. Toxicol. Chem. 18, 89-108.

Reidy, B., Haase, A., Luch, A., Dawson, K.A., Lynch, I., 2013. Mechanisms of silver nanoparticle release, transformation and toxicity: a critical review of current knowledge and recommendations for future studies and applications. Materials 6, 2295-2350.

Reisfeld, R., Saraidarov, T., Levchenko, V., 2008. Formation and structural characterization of silver nanoparticles in ormosil sol-gel films. Opt. Appl. 38, 83-92.

Sekomo, C.B., Rousseau, D.P.L., Saleh, S.A., Lens, P.N.L., 2012. Heavy metal removal in duckweed and algae ponds as a polishing step for textile wastewater treatment. Ecol. Eng. 44, 102-110.

Semaltianos, N.G., 2010. Nanoparticles by laser ablation. Crit. Rev. Solid State 35, 105-124.

Sneha, K., Sathishkumar, M., Mao, J., Kwak, I.S., Yun, Y.S., 2010. Corynebacterium glutamicum-mediated crystallization of silver ions through sorption and reduction processes. Chem. Eng. J. 162, 989-996.

Song, G., Gao, Y., Wu, H., Hou, W., Zhang, C., Ma, H., 2012. Physiological effect of anatase $\mathrm{TiO}_{2}$ nanoparticles on Lemna minor. Environ. Toxicol. Chem. SETAC 31, 2147-2152.

Turner, A., Brice, D., Brown, M.T., 2012. Interactions of silver nanoparticles with the marine macroalga, Ulva lactuca. Ecotoxicology 21, 148-154.

Üçüncü, E., Tunca, E., Fikirdeşici, Ş., Altındağ, A., 2013. Decrease and increase profile of $\mathrm{Cu}, \mathrm{Cr}$ and $\mathrm{Pb}$ during stable phase of removal by duckweed (Lemna minor $\mathrm{L}$.) Int. J. Phytoremediat. 15, 376-384.

Villaescusa, I., Fiol, N., Martinez, M., Miralles, N., Poch, J., Serarols, J., 2004. Removal of copper and nickel ions from aqueous solutions by grape stalks wastes. Water Res. 38, 992-1002.

Wiesner, M.R., Lowry, G.V., Alvarez, P., Dionysiou, D., Biswas, P., 2006. Assessing the risks of manufactured nanomaterials. Environ. Sci. Technol. 40, 4336-4345.

Wood, C.M., Hogstrand, C., Galvez, F., Munger, R.S., 1996. The physiology of waterborne silver toxicity in freshwater rainbow trout (Oncorhynchus mykiss).2. The effects of silver thiosulfate. Aquat. Toxicol. 35, 111-125.

Zhang, H.R., Li, Q.B., Lu, Y.H., Sun, D.H., Lin, X.P., Deng, X., He, N., Zheng, S.Z., 2005. Biosorption and bioreduction of diamine silver complex by Corynebacterium. J. Chem. Technol. Biotechnol. 80, 285-290. 